\title{
Changing Perspectives in the Assessment of Resectability of Hilar Cholangiocarcinoma
}

\author{
Thomas M. van Gulik and Dirk J. Gouma
}

Department of Surgery, Academic Medical Center, Amsterdam, The Netherlands

Hilar cholangiocarcinoma, also known as Klatskin's tumor, is a relatively rare tumor typically affecting the hepatic duct confluence. Surgical treatment is difficult because of central location of the tumor in the liver hilum and its intimate relationships with adjacent liver parenchyma, the portal vein, and hepatic arteries. During the past two decades, the outcome of surgical treatment has improved considerably, mainly owing to application of wider resections. ${ }^{1}$ Most hilar tumors, especially those with proximal biliary extension into the segmental bile ducts, are now resected en bloc with (extended) hemihepatectomy including the caudate lobe and excision of the portal vein bifurcation when involved. ${ }^{2-10}$ Local infiltration of the tumor confined to a small, anatomically complex area only allows limited surgical exposure lest one disrupts the tumor during surgical dissection. Surgical exploration is, therefore, currently limited to assessment of distant metastases and exploration of the hepatoduodenal ligament for involvement of the hepatic arteries, while preoperatively the approach via a left-sided or right-sided hemihepatectomy has been determined, with anticipation of portal vein resection when deemed necessary on the basis of preoperative imaging studies. Hence, whereas a more aggressive surgical approach has increased the rate of curative resections, the demands of diagnostic procedures and staging systems have increased. Herein, we point out the current issues regarding diagnosis and resect-

Received August 2, 2006; accepted February 12, 2007; published online: April 24, 2007.

Address correspondence and reprint requests to: Thomas M. van Gulik; E-mail: t.m.vangulik@amc.uva.nl

Published by Springer Science+Business Media, LLC @ 2007 The Society of Surgical Oncology, Inc. ability of this tumor and advocate assessment and treatment of these patients in dedicated centers.

Benign biliary strictures, often of inflammatory origin such as in primary sclerosing cholangitis, may mimic malignant strictures at the liver hilum. There are no imaging modalities that can reliably differentiate between a benign or malignant hilar stricture. Fine needle aspiration biopsy (FNAB) has low sensitivity (approximately 30\%) and should not be encouraged because of the risk of seeding metastases. Brush cytology obtained with ERC has limited sensitivity of $50-60 \%$, and even false positive results are reported, especially when patients have had prolonged stent therapy for biliary drainage. After longstanding pertubation, it may be difficult for the pathologist to distinguish inflammatory cells from tumor cells. So far, blood tumor markers are also of limited value, the more so since plasma levels are increased due to cholestasis, which of course is a common feature of the tumor. Hence many of our patients are operated on without confirmed diagnosis, and currently up to $15 \%$ of resected tumors are ultimately diagnosed on histopathological examination as benign, usually inflammatory lesions. ${ }^{11} \mathrm{~A}$ similar experience has been reported by other hepatobiliary units. ${ }^{12,13}$ The difficulties in establishing diagnosis preoperatively hamper the design of neoadjuvant therapies for this type of tumor. Cholangioscopic biopsy, either by the peroral or percutaneous route, is a diagnostic modality with reported high sensitivity. ${ }^{14-16}$ Although its use is presently limited because of the required endoscopic expertise, its use is to be encouraged in the differentiation between malignant and benign lesions.

Several excellent reviews dealing with diagnosis and treatment of hilar cholangiocarcinoma have 
recently been published in the medical journals. ${ }^{17,18}$ All refer to the Bismuth-Corlette classification in relation with resectability of this tumor. ${ }^{19}$ Bismuth type III tumors showing extension into the first segmental biliary ducts on one side of the liver require (extended) hemihepatectomy, whereas according to these reviews, Bismuth type IV tumors, which extend into the first segmental ducts on both sides of the liver, are considered unresectable. The anatomy of the biliary ducts at the hepatic duct confluence, however, determines whether tumor-free ductal margins can be obtained with preservation of sufficient remnant liver, even in Type IV tumors. ${ }^{7,20-22}$ Whereas the right anterior (B5/8) and right posterior (B6/7) sectorial ducts usually drain into the right hepatic duct, this duct may be short or even absent, with both right sectoral ducts draining together with the left hepatic duct directly into the common hepatic duct. A hilar tumor in this situation may directly infiltrate into the right segmental ducts and when also extending into the left segmental ducts (B2/3/4) will be classified as a Bismuth type IV tumor. Hilar resection in combination with a left hemihepatectomy potentially clears all tumor. Likewise, on the left side, the place of drainage of the segment 4 duct varies, and when located close to the confluence, is readily infiltrated by tumor. When a tumor also extends into the right segmental ducts, the tumor is diagnosed as a type IV tumor. When performing extended right hemihepatectomy, segment 4 is completely removed, leaving a tumor-free resection margin on the bile ducts of segments 2 and 3. Alternatively, the cranial part of segment 4 may be preserved, leaving a free margin on the proximal part of the bile duct of segment 4. Hence, it should be emphasized among our referring colleagues that not every Klatskin type IV tumor is by definition unresectable and that each patient should be assessed on an individual basis.

The Bismuth classification system takes into account extension of tumor into the right and left biliary system, with segment 4 lying anterior to the tumor. Hilar tumors, however, equally extend in posterior direction, involving the usually short bile ducts of the caudate lobe (segment 1). Resection of the caudate lobe along with all or part of segment 4 , therefore, is mandatory to remove all tumor. ${ }^{6,7,23}$ The Bismuth classification also does not take into account liver parenchymal invasion, vascular invasion in portal vein or hepatic arteries, and metastases, all crucial criteria in the assessment of resectability of Klatskin tumors. In addition to some form of cholangiography, preferably noninvasively as with magnetic resonance cholangiography (MRC), cross-sectional imaging modalities such as computed tomography (CT) and magnetic resonance imaging (MRI) are therefore essential to examine these features. Most patients referred with the suspicion of hilar carcinoma already have biliary stents placed by the referring gastroenterologists. Because the assessment of biliary tumor is often hampered by the presence of biliary stents, a complete work-up before considering stent placement is therefore, advocated. Although controversial in other hepato-biliary pancreatic (HPB) tumors, we have continued staging laparoscopy in the assessment of hilar cholangiocarcinoma, as a laparotomy can be avoided in 25-40\% of patients, mostly because of the detection of small peritoneal or liver metastases. ${ }^{24,25}$

There clearly is a need for a staging system that allows selection of surgical candidates, based on proximal tumor extent, tumor mass, involvement of portal vein and/or hepatic arteries, and evidence of metastases. The TNM system is more useful for posthoc analysis after histopathological examination of the resection specimen. ${ }^{26}$ A preoperative staging system has been recently proposed by the surgical group of Memorial Sloan-Kettering Cancer Center in New York, based on local, tumor-related factors. ${ }^{27}$ Most importantly, the decision to explore or otherwise treat a patient with hilar cholangiocarcinoma should be made by a multidisciplinary team consisting of experienced hepatobiliary surgeons, endoscopists, and radiologists. It is time that the surgical community combines efforts so that patients with this scarce and difficult tumor are assessed and treated in specialized centers.

\section{REFERENCES}

1. Seyama Y, Kubota K, Sano K, Noie T, Takayama T, Kosuge $\mathrm{T}$, Makuuchi M. Long-term outcome of extended hemihepatectomy for hilar bile duct cancer with no mortality and high survival rate. Ann Surg 2003; 238:73-83.

2. Nishio H, Nagino M, Nimura Y. Surgical management of hilar cholangiocarcinoma; the Nagoya experience. HPB Surg 2005; 7(4):26.

3. Neuhaus P, Jonas S, Settmacher U, Thelen A, Benckert C, Lopez-Hanninen E, Hintze RE. Surgical management of proximal bile duct cancer: extended right lobe resection increases resectability and radicality. Langenbecks Arch Surg 2003; 388:194-200.

4. Dinant S, Gerhards MF, Rauws EAJ, Busch ORC, Gouma DJ, Van Gulik TM. Improved outcome of resection of hilar cholangiocarcinoma (Klatskin tumor). Ann Surg Oncol 2006; 13(6):872-80.

5. Bengmark S, Ekberg H, Evander A, Klofver-Stahl B, Tranberg KG. Major liver resection for hilar cholangiocarcinoma. Ann Surg 1988; 207:120-5. 
6. Mizumoto R, Kawarada Y, Suzuki H. Surgical treatment of hilar carcinoma of the bile duct. Surg Gynecol Obstet 1986; 162:153-8.

7. Nimura Y, Hayakawa N, Kamiya J, Kondo S, Shionoya S. Hepatic segmentectomy with caudate lobe resection for bile duct carcinoma of the hepatic hilus. World J Surg 1990; 14:535-44.

8. Sakaguchi S, Nakamura S. Surgery of the portal vein in resection of cancer. Surgery 1986; 99:344-9.

9. Nimura Y, Hayakawa, Kamiya J, Maeda S, Kondo S, Yasui A, Shionoya S. Combined portal vein and liver resection for carcinoma of the biliary tract. Br J Surg 1991; 78:727-31.

10. Ebata T, Nagino M, Kamiya J, Uesaka K, Nagasaka $T$, Nimura Y. Hepatectomy with portal vein resection for hilar cholangiocarcinoma. Audit of 52 consecutive cases. Ann Surg 2003; 238:720-7.

11. Gerhards MF, Vos P, Van Gulik TM, Rauws EAJ, Bosma A, Gouma DJ. Incidence of benign lesions in patients resected for suspicious hilar obstruction. Br J Surg 2001; 88:48-51.

12. Knoefel WT, Prenzel KL, Peiper M, Hosch SB, Gundlach M Eisenberger CF, Strate T, Scheunemann P, Rogiers X, Izbicki JR. Klatskin tumors and Klatskin mimicking lesions of the biliary tree. Eur J. Surg Oncol 2003; 29(8):658-61.

13. Corvera CU, Blumgart LH, Darvishian F, Klimstra DS, DeMatteo R, Fong Y, D’Angelica M, Jarnagin WR. Clinical and pathological features of proximal biliary strictures masquerading as hilar cholangiocarcinoma. J Am Coll Surg 2005; 201:862-9.

14. Shim CS, Neuhaus H, Tamada K. Direct cholangioscopy. Endoscopy 2003; 752-758.

15. Nimura Y, Shionoya S, Hayakawa N, Kamiya J, Kondo S, Yasui A. Value of percutaneous transhepatic cholangioscopy (PTCS). Surg Endosc 1988; 2:213-9.

16. Murata T, Nagasaka T, Kamiya J, Nimura Y, Wakai K Yoshida K, Nakashima N. p53 labeling index in cholangioscopic biopsies is useful for determining spread of bile duct carcinomas. Gastrointest Endosc 2002; 56:688-95.
17. Lazaridis KN, Gores GJ. Cholangiocarcinoma. Gastroenterol 2005; 128:1655-67.

18. Khan SA, Thomas HC, Davidson BR, Taylor-Robinson SD. Cholangiocarcinoma [review]. Lancet 2005; 366:1303-14

19. Bismuth H, Corlette MB. Intrahepatic cholangioenteric anastomosis in carcinoma of the hilus of the liver. Surg Gynecol Obstet 1975; 140:70-8.

20. Ohkubo M, Nagino M, Kamiya J, Yuasa N, Oda K, Arai T, Nishio H, Nimura Y. Surgical anatomy of the bile ducts at the hepatic hilum as applied to living donor liver transplantation. Ann Surg 2004; 239:82-86.

21. Nimura Y. Staging of biliary carcinoma: cholangiography and cholangioscopy. Endoscopy 1993; 25:76-80.

22. Nimura $\mathrm{Y}$, Hayakawa N, Kamiya J, Kondo S, Nagino M, Kanai M. Hilar cholangiocarcinoma-surgical anatomy and curative resection. J Hepatobiliary Pancreat Surg 1995; 2:23948.

23. Dinant S, Gerhards MF, Busch ORC, Obertop H, Gouma DJ, Van Gulik TM. The importance of complete excision of the caudate lobe in resection of hilar cholangiocarcinoma. $H P B$ 2005; 7(4):263-7.

24. Tilleman EH, de Castro SM, Busch OR, Bemelman WA, van Gulik TM, Obertop H, Gouma DJ. Diagnostic laparoscopy and laparoscopic ultrasound for staging of patients with malignant proximal bile duct obstruction. J Gastrointest Surg 2002; 6(3):426-30.

25. Weber SM, DeMatteo RP, Fong Y, Blumgart LH, Jarnagin WR. Staging laparoscopy in patients with extrahepatic biliary carcinoma. Analysis of 100 patients. Ann Surg 2002; 235:3929.

26. Launois B, Terblanche J, Lakeshal M, Catheline JM, Bardaxoglou E, Landen S, Campion JP, Sutherland F, Meunier B. Proximal bile duct cancer: high resectability rate and 5-year survival. Ann Surg 1999; 230:266-75.

27. Jarnagin WR, Winston C. Hilar cholangiocarcinoma; diagnosis and staging. $H P B$ 2005; 7(4):263-7. 